\title{
A hydrocarbon enrichment model and prediction of favorable accumulation areas in complicated superimposed basins in China
}

\author{
Pang Xiongqi ${ }^{1,2 *}$, Meng Qingyang ${ }^{3}$, Jiang Zhenxue ${ }^{1,2}$, Liu Luofu ${ }^{1,2}$ \\ and Lü Xiuxiang ${ }^{1,2}$ \\ ${ }^{1}$ State Key Laboratory of Petroleum Resources and Prospecting, China University of Petroleum, Beijing 102249, China
${ }^{2}$ Basin and Reservoir Research Center, China University of Petroleum, Beijing 102249, China
${ }^{3}$ Research Institute of Petroleum Exploration and Development, PetroChina, Beijing 100083, China
}

(C) China University of Petroleum (Beijing) and Springer-Verlag Berlin Heidelberg 2010

\begin{abstract}
The geologic conditions of superimposed basins in China are very complicated. This is mainly shown by multi-phase structural evolution, multiple sets of source-reservoir-cap rock combinations, multiple stages of hydrocarbon generation and expulsion from source rocks, multi-cycle hydrocarbon enrichment and accumulation, and multi-phase reservoir adjustment and reconstruction. The enrichment, accumulation and distribution of hydrocarbon is mainly controlled by the source rock kitchen, paleoanticline, regional cap rock and intensity of tectonic movement. In this paper, the T-BCMS model has been developed to predict favorable areas of hydrocarbon accumulation in complicated superimposed basins according to time and spatial relationships among five key factors. The five factors include unconformity surface representing tectonic balancing (B), regional cap rock representing hydrocarbon protection $(\mathrm{C})$, paleo-anticline representing hydrocarbon migration and accumulation $(\mathrm{M})$, source rock kitchen representing hydrocarbon generation and expulsion $(\mathrm{S})$ and geological time $(\mathrm{T})$. There are three necessary conditions to form favorable areas of hydrocarbon accumulation. First, four key factors BCMS should be strictly in the order of BCMS from top to bottom. Second, superimposition of four key factors BCMS in the same area is the most favorable for hydrocarbon accumulation. Third, vertically ordered combination and superimposition in the same area of BCMS should occur at the same geological time. The model has been used to predict the most favorable exploration areas in Ordovician in the Tarim Basin in the main hydrocarbon accumulation periods. The result shows that $95 \%$ of the discovered Ordovician hydrocarbon reservoirs are located in the predicted areas, which indicates the feasibility and reliability of the key factor matching T-BCMS model for hydrocarbon accumulation and enrichment.
\end{abstract}

Key words: Complicated superimposed basin, key factor matching, T-BCMS model, favorable area for hydrocarbon accumulation, hydrocarbon distribution prediction

\section{Introduction}

A series of large-scale complicated superimposed basins developed in west China, including the Tarim, Junggar, Qaidam and Turpan-Hami basins. A long evolutionary history, complete strata record, broad sedimentary formation and multiple unconformity surfaces are features of the Tarim Basin, which is typical of complicated superimposed basins in west China. Therefore, in order to discuss the issue simply, the Tarim Basin is taken as an example to study the hydrocarbon accumulation and distribution model under the control of multiple geological factors.

*Corresponding author. email: pangxq@cup.edu.cn Received September 4, 2009

\section{Five basic geological characteristics of complicated superimposed basins}

\subsection{Multiple tectonic movements}

Multiple tectonic movements occurred in the superimposed basins in west China. Nine tectonic movements occurred in the Tarim Basin, including six large-scale tectonic movements: Tarim, late Caledonian, early Hercynian, late Hercynian, Indo-Chinese and late Yanshan movements (Pang et al, 2002). Five tectonic movements occurred in the Junggar and Qaidam basins and four in the Turpan-Hami Basin. The tectonic movements are recorded by the unconformities in seismic sections. Regional angular unconformities indicate intense tectonic movements, while locally parallel 
unconformities indicate weak tectonic movements. The thickness of eroded underlying strata can be estimated from the occurrence, physical properties and geochemical characteristics of strata both above and below the unconformity, which can provide a geological basis for the research into the intensity and mode of tectonic movements (Pang et al, 2006).

\subsection{Multiple sets of source-reservoir-cap rock combination}

Multiple sets of source-reservoir-cap rock combinations commonly developed in superimposed basins in west China. There are six sets in the Junggar Basin, four in the Qaidam Basin (Wang et al, 1997) and five in the Turpan-Hami Basin (Yuan et al, 2002). In the Tarim Basin, four sets of sourcereservoir-cap rock combinations developed in the Paleozoic, including the Cambrian source-reservoir-cap, the Ordovician source-reservoir-cap, the Cambrian-Ordovician source and Silurian reservoir-cap, and the Cambrian-Ordovician source and Carboniferous reservoir-cap (Zhang et al, 2008). The Cambrian gypsum, thick black mudstone at the top of the Ordovician, Silurian red mudstone and the Carboniferous under-compacted sandy mudstone are all good regional cap rocks for preserving hydrocarbons in the Tarim Basin. The Cambrian dolomite, Ordovician carbonate reef deposits and karst terrain, Silurian littoral facies sandstone and Donghe sandstone at the base of the Carboniferous are all good regional reservoirs, which are widely developed in the basin. Good matches of reservoir and cap rocks create good conditions for hydrocarbon accumulation.

\subsection{Hydrocarbon expulsion from source rocks in multiple areas}

Hydrocarbon expulsion from source rocks in multiple areas in the same geological period is one of the characteristics of superimposed basins. The widely distributed Cambrian and Ordovician are the two main sets of source rocks developed in the Tarim Basin (Gao et al, 2006; Zhang et al, 2005). Influenced by tectonic movements, the burial depths of the same source rocks vary in different areas within the same epoch. When the burial depth of the source rock was very large, it usually generated gas. When the burial depth of the source rock was moderate, it usually generated oil. When the burial depth was relatively small, the source rock is not yet mature. The hydrocarbon expulsion centers of the two sets of source rocks in the same period were different. The source kitchens of the same source rock in different periods showed regular migration characteristics. The research results showed that the hydrocarbon expulsion center was located in the Manjiaer Depression in the Caledonian epoch, in the Southwest Depression in the Hercynian epoch, and migrated to the Awati Depression and Tazhong Uplift in the IndoChinese epoch. The favorable hydrocarbon accumulation areas in different periods changed with the migration of the source kitchen.

\subsection{Multiple cycles of hydrocarbon accumulation}

Every large-scale tectonic movement led to uplift and erosion in some places and large-scale subsidence and sedimentation in other places. In the areas of subsidence, because of the gradual increase of burial depth, the underlying source rock began to generate and expel hydrocarbons. When all the other conditions were suitable, hydrocarbons would be accumulated. Each tectonic movement in complicated superimposed basins would result in a new round of hydrocarbon accumulation. Research results showed that there were three hydrocarbon accumulation stages in the Junggar Basin (Chen et al, 2002) and two stages in both the Qaidam Basin (Dang et al, 2004) and the TurpanHami Basin (Jiang et al, 2000). Based on tectonic evolution characteristics in the Tarim Basin, the concept of multistage hydrocarbon accumulation was presented and three hydrocarbon accumulation stages in the Tarim Basin were described (Jia and Wei, 2002). Lü et al (1996) presented a theory of multi-cycle hydrocarbon accumulation, based on the evolution and matching of geological conditions and reported three hydrocarbon accumulation cycles in the Tarim Basin. Some other scholars have instead classified the hydrocarbon accumulation in the Tarim Basin into four stages through geological and geochemical analysis (Liu et al, 2000; Zhang et al, 2000; Zhao et al, 2004; Zhao and Li, 2002; Zhao et al, 2002; Ma et al, 2005; Zhang et al, 2006).

\subsection{Multiple adjustments and reconstructions after hydrocarbon accumulation}

On one hand the tectonic movements in superimposed basins led to multiple stages or cycles of hydrocarbon accumulation, on the other hand every later tectonic movement would adjust, reconstruct, and even destroy earlier hydrocarbon reservoirs. Most of the discovered reservoirs in west China have been adjusted, reconstructed and destroyed to a certain degree. When the reservoir location migrates, it is called adjustment. The Carboniferous sandstone reservoir in the Hadexun area of the Tarim Basin is a good example. Owing to the migration speed to the east of the tectonic top being higher than the flowing speed of internal fluids, the migrating hydrocarbons are found in the west slope. When the composition of the reservoir is changed, it is called reconstruction. For example, biodegradation and pyrolysis in the Tahe-Lunnan Oilfield changed the original composition of the reservoir substantially. When the size of the reservoir decreases or the reservoir even disappears, it is called destruction. The asphalt sands widely distributed in the Silurian strata of Tarim Basin show that large-scale hydrocarbon accumulations were destroyed. Usually, the formation and evolution of reservoirs were followed by adjustment of location, reconstruction of composition and decrease in scale or even destruction of reservoirs.

\section{Four key geological factors control hydrocarbon accumulation in complicated superimposed basins}

Strictly, hydrocarbon accumulation in any basin is controlled by six factors: source rock, reservoir rock, cap rock, migration, entrapment and preservation. For the complicated superimposed basins in west China, hydrocarbon 
enrichment and accumulation are controlled by four key factors. These are source rock (S), buried mountain (M), cap rock (C) and tectonic movement intensity (B) (Pang et al, 2007). Clearly, it is much easier to study a combination of four key controlling factors than one of six factors. So, predicting favorable exploration areas or potential exploration direction based on only four factors can be substantially faster and more efficient.

\subsection{Source rock kitchen restricting the boundary of hydrocarbon expulsion and migration (S)}

The source rock kitchen means the central area of hydrocarbon expulsion on a large scale from source rock in a specific hydrocarbon accumulation stage, and also refers to the effective hydrocarbon supply area of source rock in hydrocarbon accumulation stages. It can usually be measured by the hydrocarbon expulsion intensity of the source rock. The area in which the effective hydrocarbon expulsion intensity is zero is the boundary of the source rock kitchen. In the center of the source rock kitchen, the hydrocarbon expulsion intensity is the highest. The research results show that the hydrocarbon expelled from the source rock kitchen will migrate and accumulate in reservoirs. The statistics of 73 large-medium oil and gas fields in China show that the distance between gas fields and the source rock kitchen is up to $100 \mathrm{~km}$, and that between oil fields and the source rock kitchen is not more than $40 \mathrm{~km}$ (Fig. 1). So, from the central area of hydrocarbon expulsion from source rock, we can easily estimate the distances within which large-medium oil and gas fields are likely to be formed. This will provide an empirical guide to predicting favorable hydrocarbon accumulation areas.

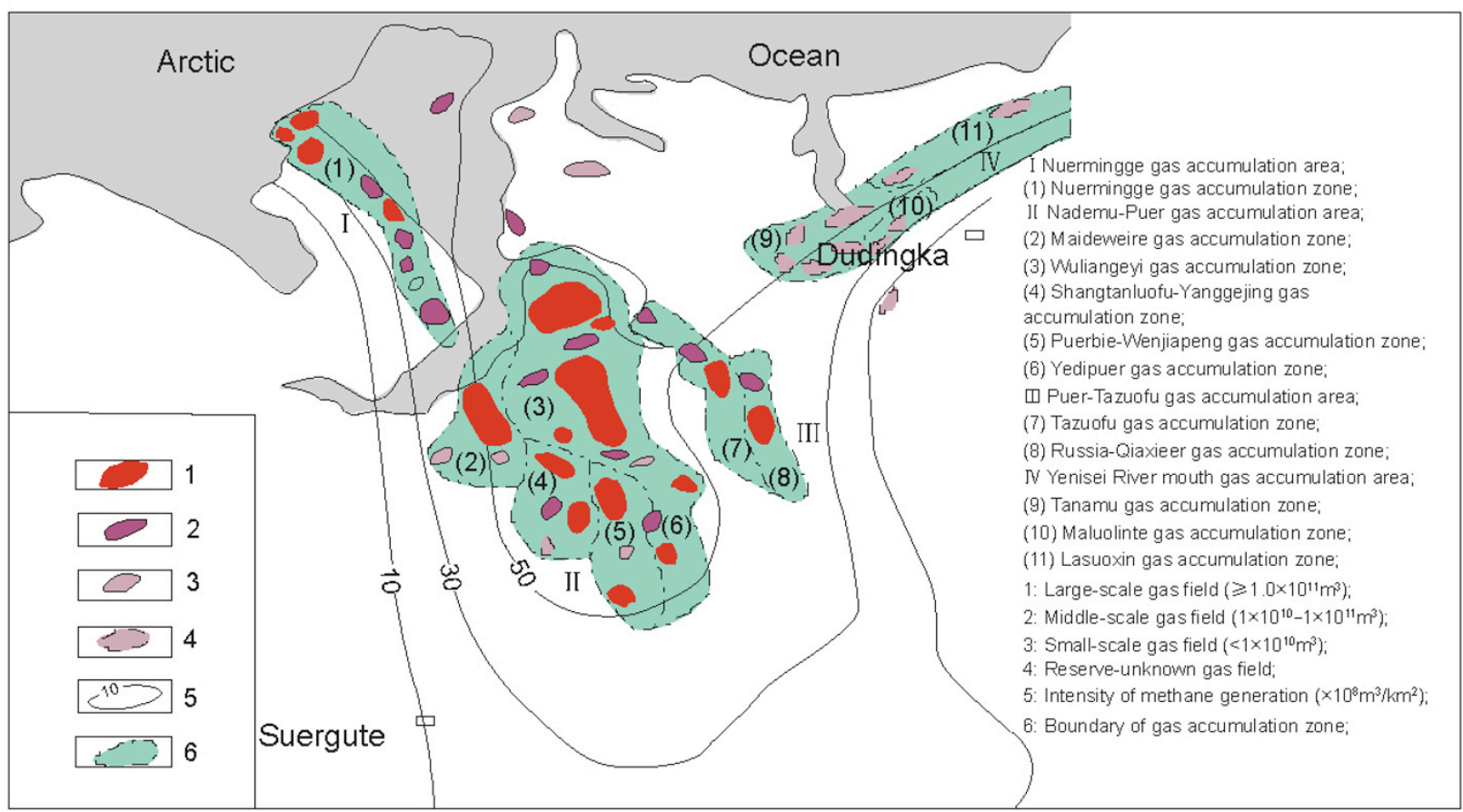

(a) Relationship between large-middle scale gas fields and gas-generation intensity in the north of the West Siberian Basin

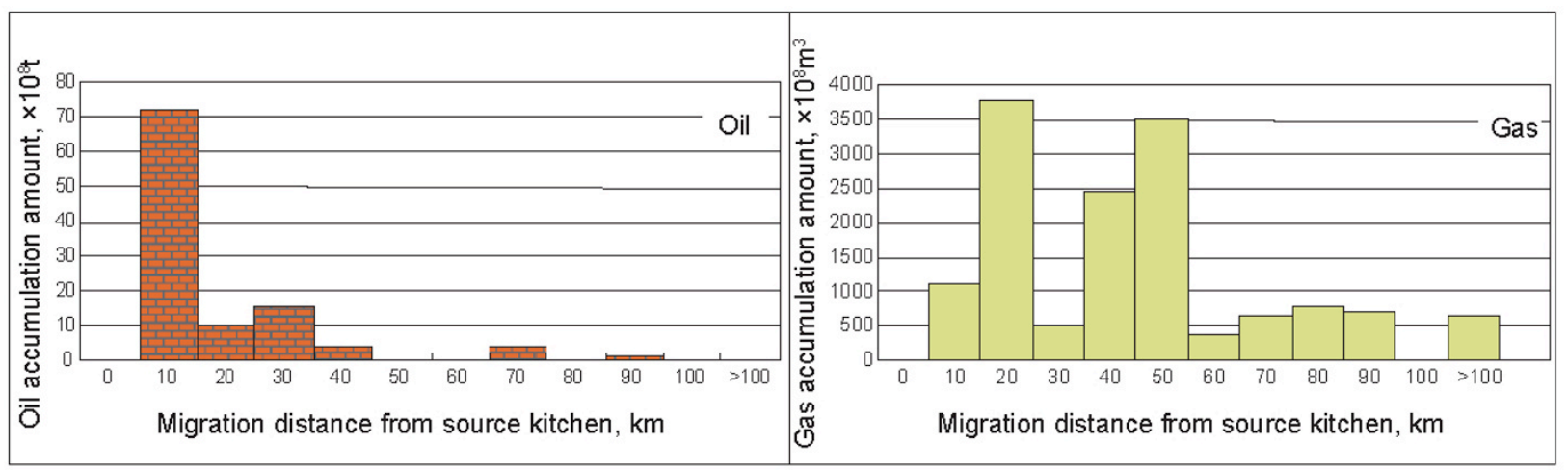

(b) Statistics of oil/gas migration distance in large-middle scale oil/gas fields in China

Fig. 1 Examples of source rock controlling hydrocarbon accumulation 


\subsection{Paleo-anticline restricting hydrocarbon enrichment areas $(M)$}

The control of paleo-anticlines on the formation and distribution of reservoirs has been accepted by many scholars (Xu, 2004; Han et al, 2006; Zhang and Jia, 1997; $\mathrm{Xu}, 2006$; Zhao et al, 2007). The basic principle is that the paleo-anticline has the characteristics of low potential. The hydrocarbons expelled from source rocks around the paleoanticline will migrate from the surrounding to the uplift, from bottom to top and from a high potential area to a low potential area under the effect of buoyancy. During this process, hydrocarbons will accumulate and form reservoirs when meeting suitable traps. The control of paleo-anticlines on hydrocarbon formation and distribution is mainly shown as a series of favorable traps developed above and below unconformity surfaces (Fig. 2). The basic model of traps developed above unconformity surfaces is that a drape anticline usually developed on top of the paleo-anticline, overlap traps usually developed around the top of the paleoanticline, and sandstone traps usually developed in the slope edge strata. The basic model of traps developed below unconformity surfaces is that stratigraphic traps of weathering crust type are usually developed on top of the paleo-anticline, stratigraphic traps of carbonate reef deposits and karst terrains are usually developed in the slope on the top of the paleo-

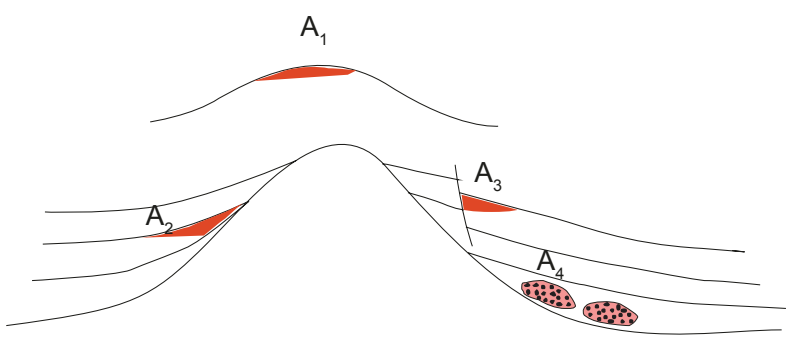

(a) Model of paleo-anticline controlling hydrocarbon (strata above unconformity)

$A_{1}$ : Drape anticline reservoir

$A_{2}$ : Stratigraphic overlap reservoir

$A_{3}$ : Fault block reservoir

$\mathrm{A}_{4}$ : Turbidite sandstone reservoir

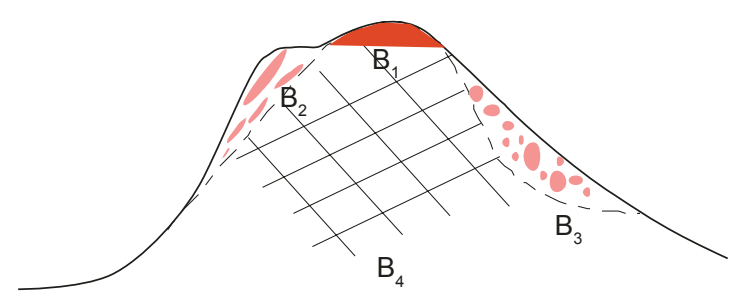

(b) Model of paleo-anticline controlling hydrocarbon (strata below unconformity)

$B_{1}$ : Weathering crust reservoir

$\mathrm{B}_{2}$ : Reef flat reservoir

$\mathrm{B}_{3}$ : Cavernous reservoir

$\mathrm{B}_{4}$ : Fractured reservoir

Fig. 2 Conception model of paleo-anticline controlling hydrocarbon accumulation anticline, and fracture type structural traps usually developed inside the buried hill. Research showed that different types of traps formed different types of reservoirs. The proportion of different types of reservoirs in all traps differs depending on the paleo-anticline, petroliferous property, productivity and reserves. Analyzing the formation and evolution characteristics of different types of paleo-anticlines in complicated superimposed basins has great significance in predicting the formation, evolution and distribution of reservoirs. Buried mountain (or paleo-anticline) is abbreviated to $\mathrm{M}$, which is favorable for reservoir and trap development.

\subsection{Regional cap rock restricting vertical intervals of hydrocarbon accumulation $(C)$}

The vertical distribution of hydrocarbon in complicated superimposed basins is controlled both by regional cap rock and faulting. The hydrocarbons expelled from deep source rocks migrated along faults, and when they met regional cap rock, they accumulated in reservoirs below the regional cap rock. If a later fault cut or destroyed the lower regional cap rock, hydrocarbons would migrate upward along the fault and accumulate in reservoirs below the shallower regional cap rock. If hydrocarbons migrated along the fault without the protection of a regional cap rock, the hydrocarbons would flow to the surface and be destroyed. Different regional cap rocks have different abilities to retain hydrocarbons (Tong and Niu, 1989). Generally speaking, large thickness, high plasticity and unbroken regional cap rock strongly favor retention of hydrocarbons (Fig. 3).

\subsection{Tectonic movement intensity restricting the degree of hydrocarbon accumulation (B)}

The tectonic movements after hydrocarbon accumulation adjust, reconstruct and destroy the previously formed reservoirs. The more intense the tectonic movements, the higher degree of adjustment, reconstruction and destruction of reservoirs. The tectonic movement intensity can be represented by the thickness of eroded strata, dip of strata and displacement of faults. The research results show that the greater the thickness of the eroded overlying strata, the larger the amount of hydrocarbon destroyed in the underlying strata. Generally speaking, when the overlying strata were thoroughly eroded or the regional cap rock was thoroughly destroyed, the hydrocarbon accumulations in underlying strata were also thoroughly destroyed. The more intense the folding in the strata, the more hydrocarbons were destroyed. When the fold dip is more than $90^{\circ}$, the hydrocarbon may be thoroughly destroyed. The more intense the faulting or the larger the fault displacement, the more hydrocarbons may be destroyed. When the fault displacement is more than the thickness of the regional cap rock, the hydrocarbon may be thoroughly destroyed. Statistics show that the petroliferous property of early formed reservoirs is correlated with erosion thickness caused by tectonic movements in the Tarim Basin. When the erosion thickness is less than $50 \mathrm{~m}$, the productivity is relatively high, which is favorable for hydrocarbon accumulation and preservation. Erosion thickness of more than $200 \mathrm{~m}$ is unfavorable for hydrocarbon accumulation and preservation and only oil patches and traces are discovered 

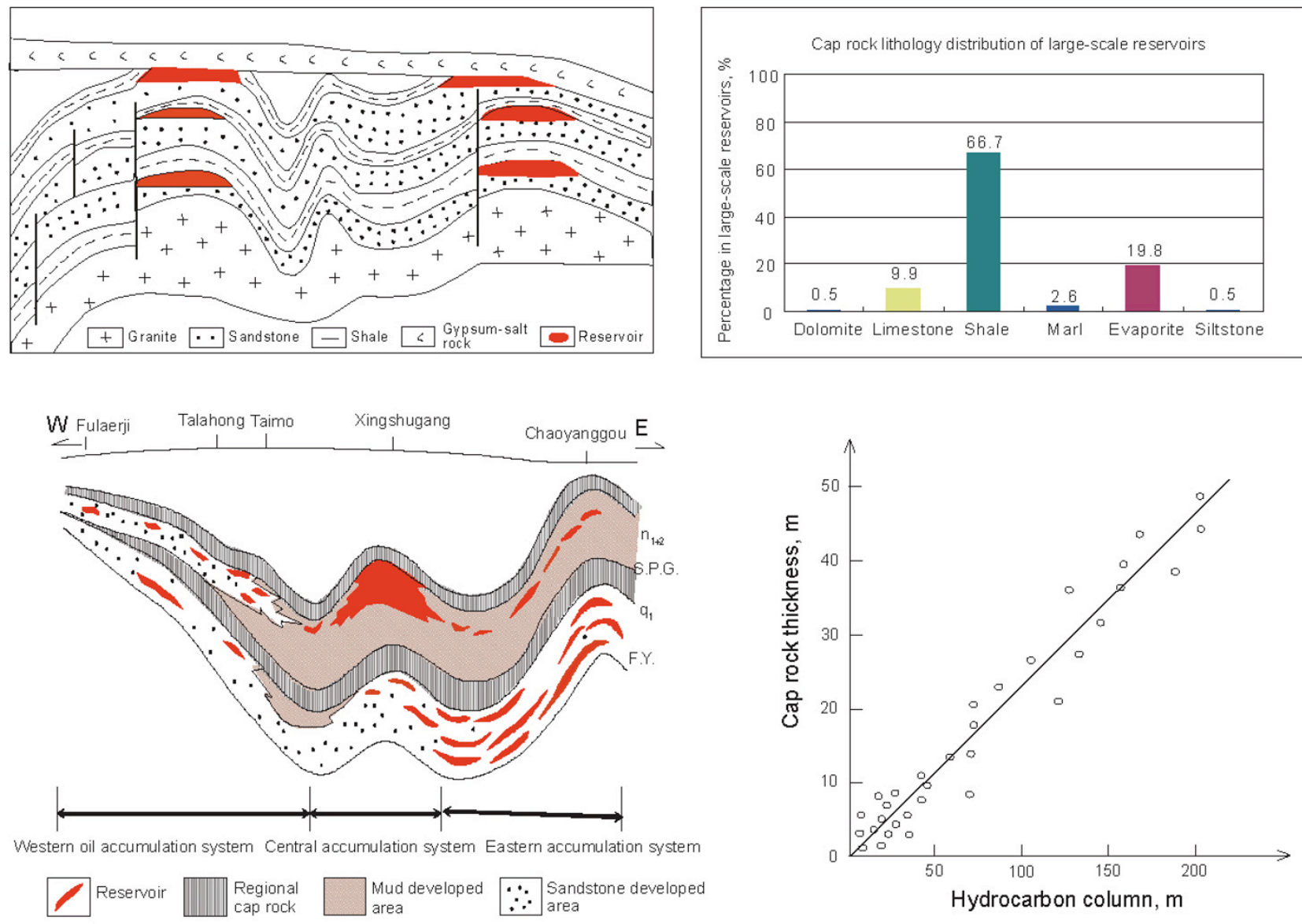

Fig. 3 Examples of regional cap rock controlling hydrocarbon accumulation

in most of the wells. When the erosion thickness is between $50 \mathrm{~m}$ and $200 \mathrm{~m}$, the productivity is the highest, which is the most favorable for hydrocarbon accumulation and preservation. According to the erosion thickness caused by later tectonic movements, the reconstructed degree of the early formed hydrocarbon reservoirs in underlying strata can be evaluated (Fig. 4). Tectonic balance is abbreviated to $\mathrm{B}$, which is favorable for hydrocarbon accumulation and preservation.

\section{Key factor matching model of hydrocarbon accumulation in complicated superimposed basins}

Hydrocarbon accumulation in complicated superimposed basins is controlled by many geological factors (Cai, 2007; $\mathrm{Li}$ and Yan, 2007). Matching and combination of different factors lead to different hydrocarbon accumulation models and enrichment degrees.

\subsection{Vertically ordered combination of geological factors is favorable for hydrocarbon accumulation and enrichment}

When the source rock is determined, the overlying reservoir-cap rock combination ( $\mathrm{M}$ in the lower section and $\mathrm{C}$ in the upper section) is favorable for hydrocarbon migration and accumulation. If there was a large unconformity surface (B) on the top, reservoirs were adjusted, reconstructed or destroyed after accumulation. In the sedimentary profile, if there were four successive factors of $\mathrm{B}, \mathrm{C}, \mathrm{M}$ and $\mathrm{S}$ from top to bottom structurally, hydrocarbon accumulation and later adjustment, reconstruction and destruction occurred in a specific geological period, which formed a complete cycle of hydrocarbon accumulation and reconstruction. The BCMS conceptual model with vertically ordered combination is shown in Fig. 5(a). In fact, there are also other models of vertical combination of the four key factors, but the combination BCMS is the most favorable. For example, the combination BCSM is not favorable for hydrocarbon accumulation, because oil from a source rock overlying a favorable reservoir rock is unlikely to migrate downward and accumulate. The combination BSCM is also unfavorable for hydrocarbon accumulation, because the cap rock underlies the source rock and can not protect the expelled hydrocarbons. The combination BMCS is also unfavorable for hydrocarbon accumulation, because the hydrocarbons expelled from source rock would be sealed by the cap rock and could not migrate to the reservoir or trap developed in the paleoanticline (M). The combination CMSB is theoretically the most favorable for hydrocarbon accumulation, but it is rarely found in superimposed basins, especially in complicated superimposed basins, because less tectonic movement occurs after hydrocarbon accumulation, which usually exists in simple basins. The analysis above shows that the vertical combination BCMS is the most favorable model for hydrocarbon accumulation. 


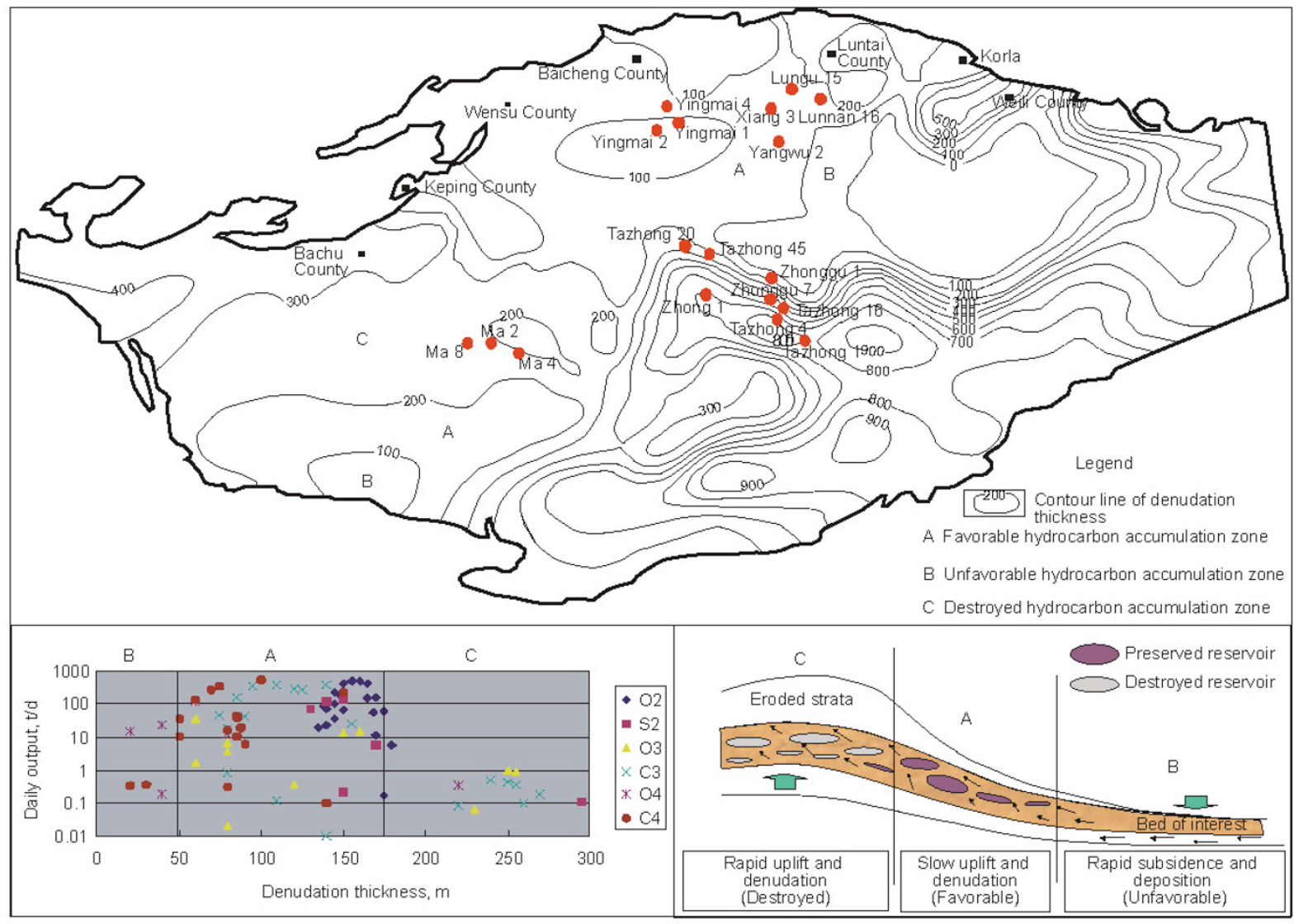

Fig. 4 Relations between thickness of eroded strata and hydrocarbon accumulation in the Tarim Basin (O2 refers to the Ordovician strata in the second accumulation stage)

\subsection{Superimposition of geological factors restrains hydrocarbon accumulation and enrichment areas}

Source rock kitchen (S), paleo-anticline (M), regional cap rock (C) and tectonic movement balancing (B) are four basic factors controlling hydrocarbon accumulation in complicated superimposed basins. If they are superimposed as BCMS in the same area, it will be favorable for hydrocarbon accumulation. If only three factors of BCMS are superimposed in the same area, the hydrocarbon enrichment probability is reduced. If only two factors of BCMS are superimposed in the same area, hydrocarbon enrichment is even less likely. If only one factor of BCMS exists in the area, enrichment has the lowest probability. In areas with none of the four factors, it is not possible to form reservoirs. In fact, for the formation and distribution of reservoirs, the four factors of BCMS are equally important. We take the area in which four factors are superimposed and vertically ordered as BCMS as the most favorable area for hydrocarbon accumulation (Fig. 5(b)).

\subsection{Connection between time and space of geological factors controls the distribution of hydrocarbon accumulation (T)}

Four basic controlling factors combined vertically and horizontally are favorable for hydrocarbon accumulation and enrichment. The interactions and connections among controlling factors in a specific geological stage can result in large-scale hydrocarbon accumulation, which is called the hydrocarbon accumulation period. The hydrocarbon accumulation period can be determined by forward analysis of geological conditions (forward analysis here means analyzing from past to present in geological time) or inferred by measuring the paleo-temperature and paleo-pressure of fluid inclusions. An ordered combination of controlling factors in space and interaction in the same geological time is the key to predicting hydrocarbon formation and distribution. The key factor model in superimposed basins can be expressed as T-BCMS. $\mathrm{T}$ stands for the time when all geological factors are matched and large-scale hydrocarbons are accumulated. B, $\mathrm{C}, \mathrm{M}$ and $\mathrm{S}$ stand for four key controlling factors respectively, including tectonic balancing, cap rock protection, paleoanticline migration and source rock generation and expulsion. Fig. 5(c) is the conceptual model of key factor matching for hydrocarbon accumulation.

\section{Prediction of favorable areas for Ordovician hydrocarbon accumulation in the Tarim Basin}

The Tarim Basin, located in Xinjiang Province in northwest China, covers an area of $560,000 \mathrm{~km}^{2}$ and is surrounded by the Tianshan Mountains to the north and the Kunlun Mountains to the south. Dozens of oil and gas fields have been discovered so far, including the Kela-2 Gas Field, Tahe-Lunnan Oilfield and the Tazhong Oilfield. Because most of the oil and gas fields have been adjusted, reconstructed and destroyed, the distribution rule is very complicated. In this paper, we are attempting an initial discussion of the concepts. 


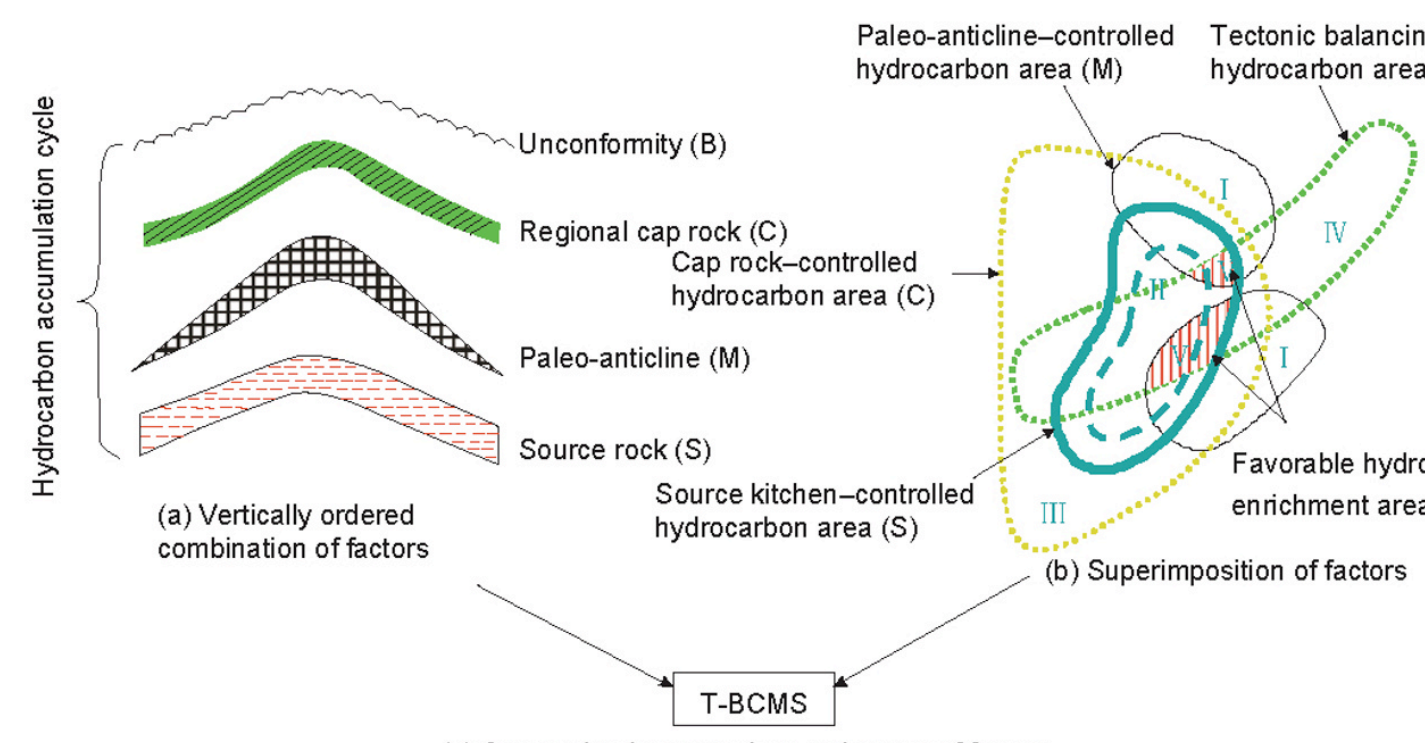

(c) Connection between time and space of factors

Fig. 5 Geological concept model (T-BCMS) of key factor matching for hydrocarbon accumulation

\subsection{Ordovician hydrocarbon exploration situation}

The Ordovician is one of the most important target layers in the Tarim Basin. Twelve oil and gas fields have already been found and the total proved reserves are nearly $1 \times 10^{9} \mathrm{t}$. The discovered oil and gas fields are mainly located in the Lunnan-Tahe area of the Tabei Uplift and the Tazhong-1 slope break belt. By the end of 2006, the discovered petroliferous areas of Lunnan-Tahe Ordovician oil and gas fields had reached $1,340 \mathrm{~km}^{2}$, and the recoverable reserves of these fields are nearly $120 \times 10^{6} \mathrm{t}$ (Liang, 2008). It is the largest Paleozoic marine carbonate oilfield in China with annual production of $5 \times 10^{6} \mathrm{t}$. By the end of 2005 , the proven and controlled reserves of the Tazhong Ordovician carbonate condensate gas field had reached $150 \times 10^{6} \mathrm{t}$ (oil equivalent). It is the first large Ordovician organic reef oilfield discovered in China (Zhou et al, 2006).

\subsection{Ordovician key controlling factors and their distribution in different stages}

On the basis of previous research (Pang et al, 2008), combined with tectonic evolution, we analyzed the distribution and development characteristics of paleoanticlines, the migration and hydrocarbon expulsion characteristics of source rock kitchens, sealing area of regional cap rocks and erosion thickness characteristics in different hydrocarbon accumulation stages. Fig. 6 is the analysis results of Ordovician controlling factors in the first hydrocarbon accumulation stage.

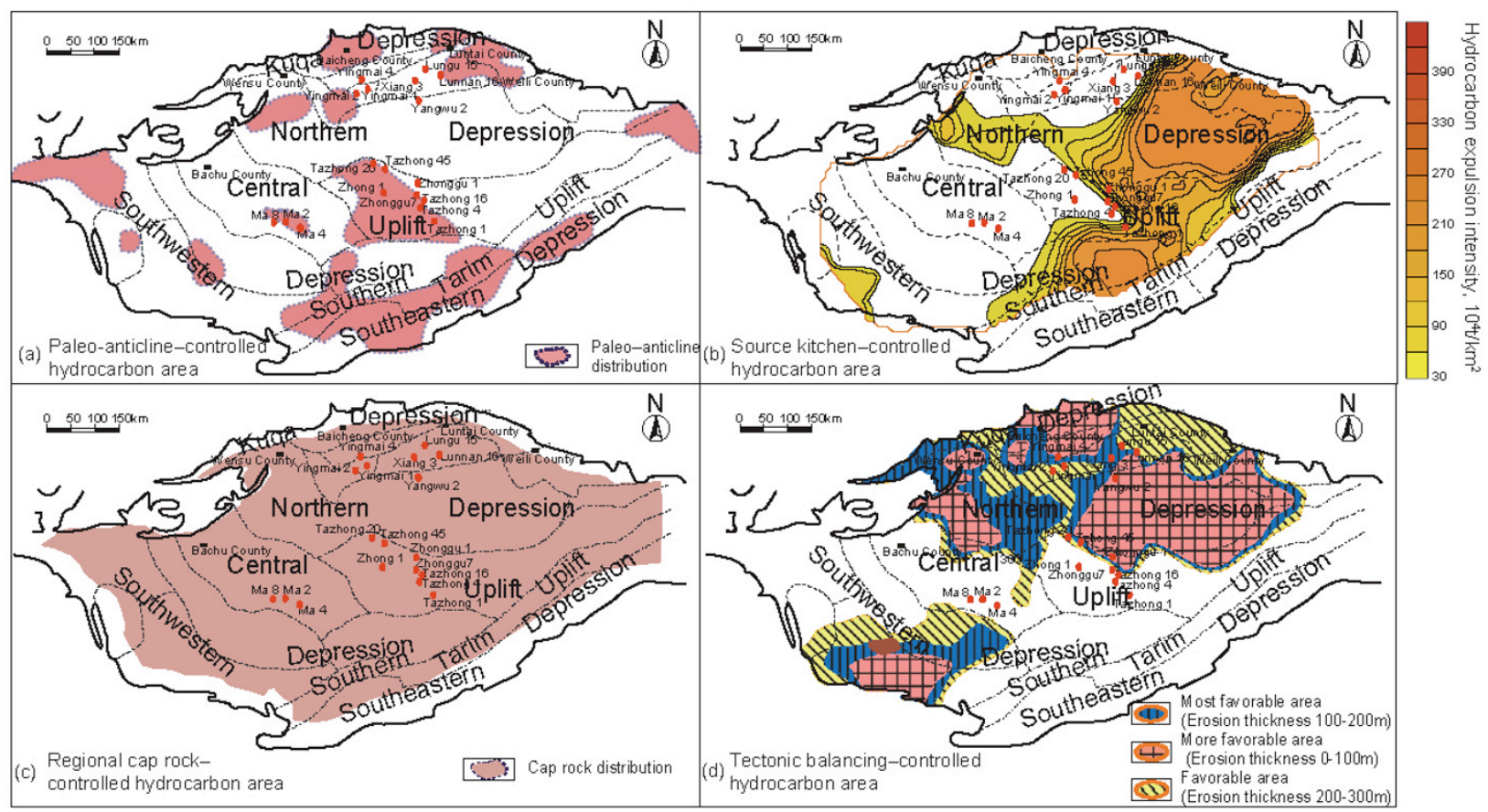

Fig. 6 Key controlling factors in the first stage of hydrocarbon accumulation in the Ordovician of the Tarim Basin 


\subsection{Prediction of the most favorable hydrocarbon accumulation areas of the Ordovician in different stages}

On the basis of the distribution of Ordovician controlling factors in the hydrocarbon accumulation stage, the T-BCMS model is used to predict the most favorable hydrocarbon accumulation areas in different stages, as shown in Fig. 7. It can be seen that the possible areas for hydrocarbon accumulation in the first stage may be distributed in the
Kongquehe slope, Wensu uplift, southern Yingmaili uplift and northern Tazhong uplift. Those in the second stage may be distributed in the Wensu uplift, Lunnan uplift, northern Tazhong uplift, northern Bachu uplift and the Tadong area. The possible areas for hydrocarbon accumulation in the third stage may be distributed in the southern Tabei uplift, Tadong area, Tazhong uplift, southern Bachu uplift and the Tangguzibasi depression. Those in the fourth stage may be distributed in the southern Tabei uplift, northern slope of Tazhong uplift, and the southern Kongquehe slope.

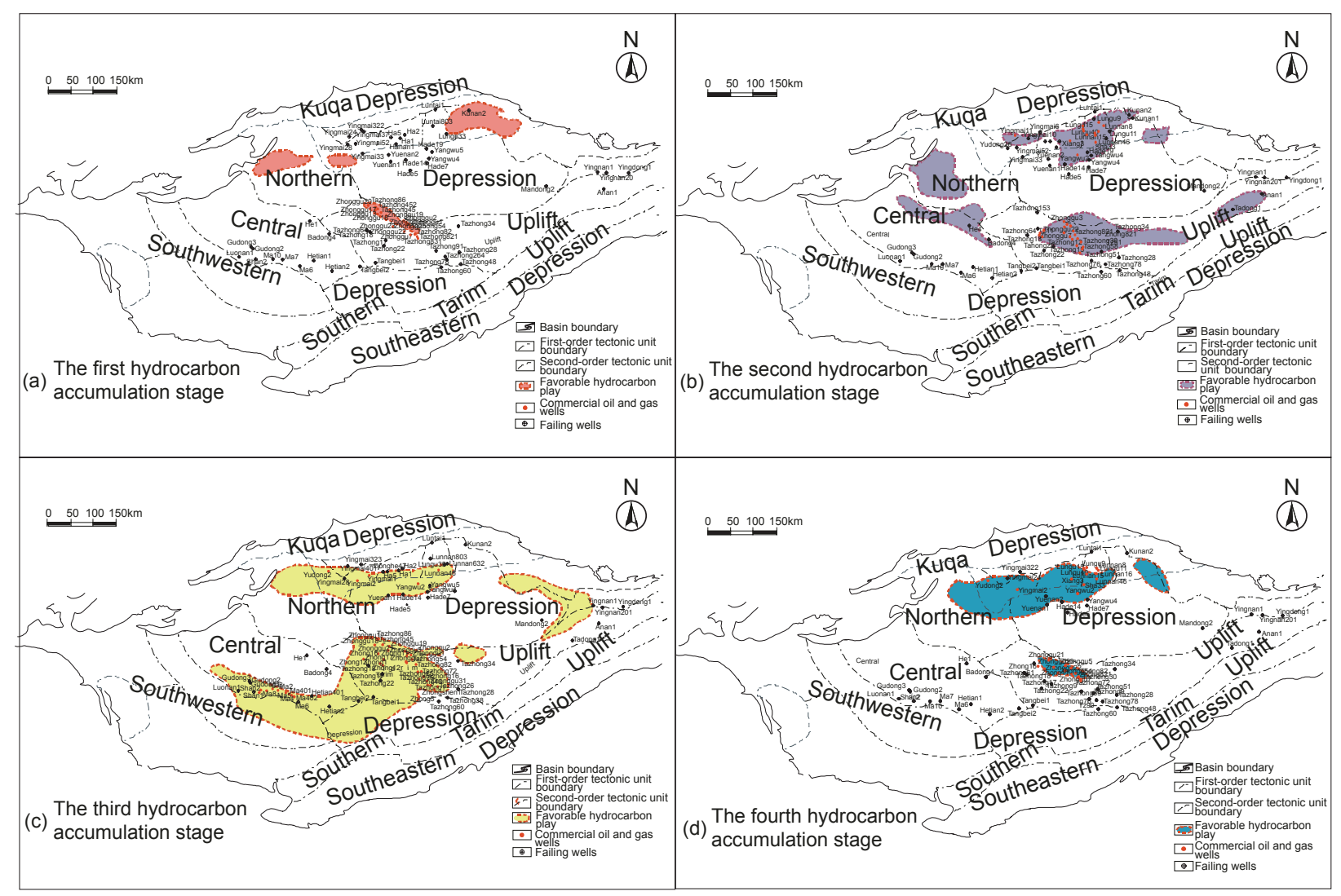

Fig. 7 Prediction maps of favorable hydrocarbon accumulation areas in different stages in the Ordovician of the Tarim Basin

\subsection{Comparison between predicted results and exploration practice in the Ordovician}

Comparing the predicted results of favorable exploration areas in the Ordovician with the discovered oil and gas fields, we find that $90 \%$ of the discovered oil and gas fields are located in the predicted favorable exploration areas, which shows that the application of the T-BCMS model in the Tarim Basin is of great reliability and feasibility (Fig. 8). It can also be seen that most of the discovered oil and gas reservoirs are formed in the third hydrocarbon accumulation stage, and the accuracy rate is $95 \%$. Next are the second and fourth hydrocarbon accumulation stages, and the accuracy rate is nearly $90 \%$. The reservoirs formed in the first hydrocarbon accumulation stage are relatively few with the accuracy rate of about $80 \%$.

Based on the statistics of dry wells, it is found that $86 \%$ of total dry wells are located outside the predicted favorable exploration areas. More than $90 \%$ of the dry wells in the first and fourth hydrocarbon accumulation stages are located outside the predicted favorable exploration areas and about $80 \%$ of the dry wells in the second and third hydrocarbon accumulation stages are located outside the predicted favorable exploration areas. Hence, the predicted results are consistent with actual exploration experience.

\section{Conclusions}

1) Hydrocarbon accumulation, enrichment and distribution in superimposed basins is mainly controlled by four factors: source rock kitchen $(\mathrm{S})$, paleo-anticline $(\mathrm{M})$, regional cap rock (C) and tectonic balancing (B). The vertically ordered combination of these factors is favorable for reservoir formation, and superimposition of these factors in the same area is favorable for hydrocarbon enrichment. The connection of these factors in three dimensions in the same geological time controls the distribution of reservoirs. The conceptual model of key factor matching is abbreviated to T-BCMS. 


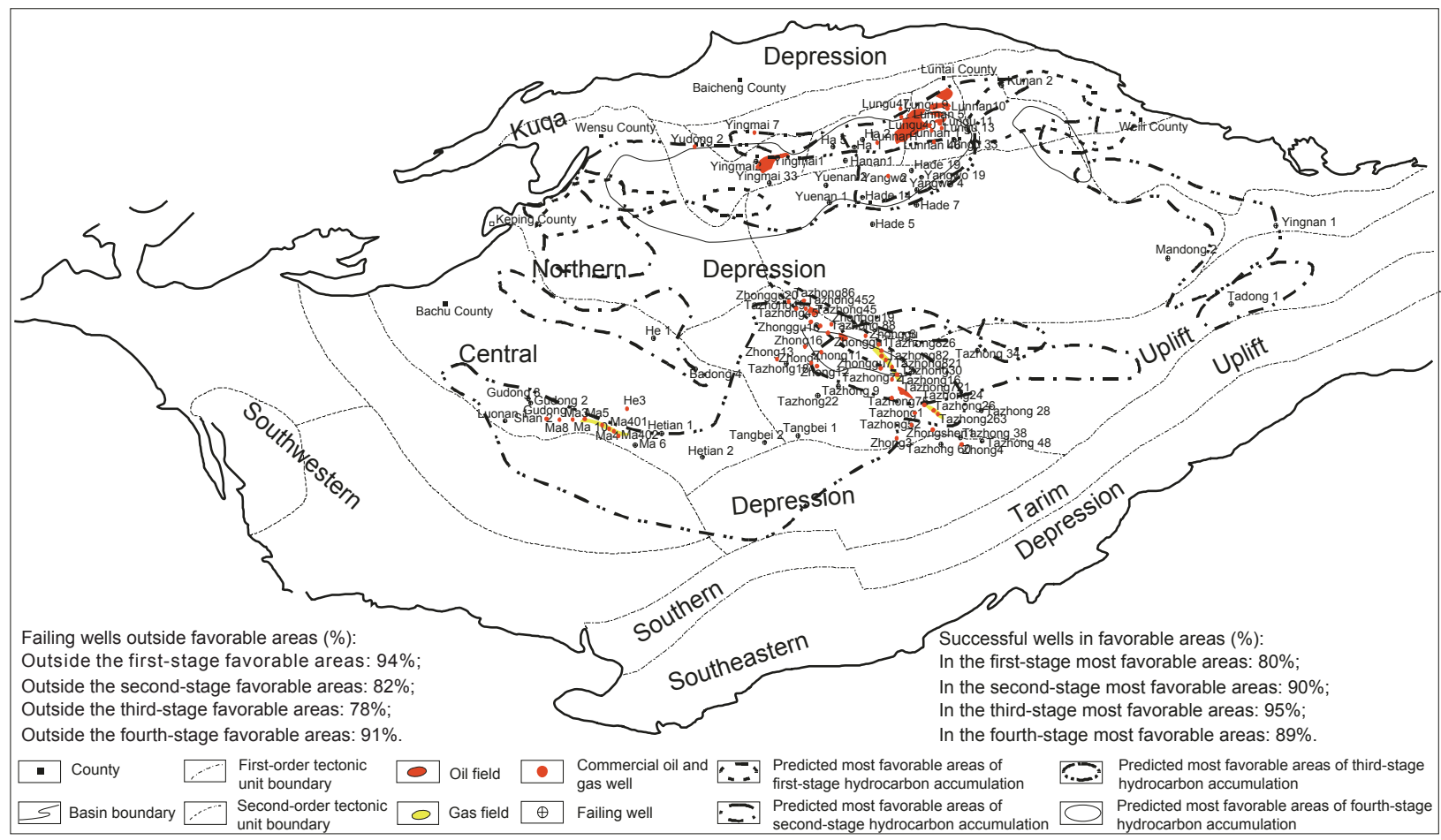

Fig. 8 Prediction maps of the most favorable hydrocarbon accumulation areas in the Ordovician of the Tarim Basin

2) The key factor matching T-BCMS model can theoretically direct the prediction of favorable hydrocarbon accumulation areas on the petroliferous basin scale. In this paper, this model is used to predict and evaluate the most favorable hydrocarbon accumulation areas of the Ordovician in four accumulation stages in the Tarim Basin. The accuracy rate of predicted results is $95 \%$ consistent with the Ordovician oil and gas fields discovered by drilling, which shows the practicality and reliability of the model.

3) The T-BCMS hydrocarbon accumulation model is only suitable for predicting favorable accumulation areas on the petroliferous basin scale and is not suitable for predicting favorable exploration targets. Two other geological aspects must be considered to predict the most favorable targets for drilling. One is to evaluate the adjustment, reconstruction and destruction of tectonic movements to the early formed hydrocarbon accumulations and then to predict the most favorable exploration zones. The other is to study trap and reservoir conditions for hydrocarbon accumulation in the most favorable exploration zone. The above two aspects need to be discussed further.

\section{Acknowledgements}

This paper was supported by the National Basic Research Program (2006CB202308).

\section{References}

Cai X Y. Main factors controlling hydrocarbon accumulation of middleand large-sized oil and gas fields and their distribution rules in the Tarim Basin. Oil and Gas Geology. 2007. 28(6): 693-702 (in Chinese)
Chen J P, Zha M, Zhou Y Q, et al. Hydrocarbon migration stages and accumulation in the Karamay Oilfield, Junggar Basin. China Offshore Oil and Gas (Geology). 2002. 16(1): 19-23 (in Chinese)

Dang Y Q, Xiong J H, Liu Z, et al. Main factors controlling hydrocarbon accumulation in the Qaidam Basin. Oil and Gas Geology. 2004. 25(6): 614-620 (in Chinese)

Gao Z Q, Fan T L, Li Y, et al. Development pattern and distribution rule of source rock of Cambrian-Ordovician in the Tarim Basin. Geoscience. 2006. 20(1): 69-77 (in Chinese)

Han J F, Wang Z M, Pan W Q, et al. Petroleum controlling theory of Lunnan paleohigh and its buried hill pool exploration technology, Tarim Basin. Petroleum Exploration and Development. 2006. 33(4): 448-454 (in Chinese)

Jia C Z and Wei G Q. Tectonic characteristics and petroliferous feature of the Tarim Basin. Chinese Science Bulletin. 2002. 47(supplement): 1-8 (in Chinese)

Jiang Z X, Pang X Q and Huang Z L. Oil and gas migration periods and accumulation processes in the Shanshan Oil Field of the Turpan-Hami Basin. Journal of the University of Petroleum, China. 2000. 24(4): 104-110 (in Chinese)

Li T J and Yan X B. Comparison and evaluation of the main factors controlling hydrocarbon accumulation in the Shaya, the Katake and the Bachu uplift, Tarim Basin. Oil and Gas Geology. 2007. 28(6): 721-730 (in Chinese)

Liang D G. Review and expectation of the discovery of Ordovician Lunnan-Tahe Oilfield, Tarim Basin. Acta Petrolei Sinica. 2008. 29(1): 153-158 (in Chinese)

Liu L F, Zhao J Z, Zhang S C, et al. Hydrocarbon filling ages and evolution of the Silurian asphalt sandstones in the Tarim Basin. Acta Sedimentologica Sinica. 2000. 18(3): 475-480 (in Chinese)

Lü X X, Zhang Y W and Jin Z J. Discussion of the hydrocarbon accumulation cycle in the Tarim Basin. Chinese Science Bulletin. 1996. 41(22): 2064-2067 (in Chinese)

Ma A L, Zhang S C, Zhang D J, et al. New advancement in study of reservoiring periods. Oil and Gas Geology. 2005. 26(3): 271-277 (in 
Chinese)

Pang X Q, Gao J B, Lü X X, et al. Reservoir accumulation patterns of multi-factor recombination and procession superimposition and its application in Tarim Basin. Acta Petrolei Sinica. 2008. 29(2): 159 166 (in Chinese)

Pang X Q, Gao J B and Meng Q Y. A discussion of the relationship between tectonization and hydrocarbon accumulation and dissipation in the platform-basin transitional area of the Tarim Basin. Oil and Gas Geology. 2006. 27(5): 594-603 (in Chinese)

Pang X Q, Jin Z J, Jiang Z X, et al. Evaluation of hydrocarbon resources of superimposed basins and its significance. Petroleum Exploration and Development. 2002. 29(1): 1-14 (in Chinese)

Pang X Q, Luo X R, Jiang Z X, et al. Advances and problems in hydrocarbon accumulation research of complicated superimposed basins in western China. Advances in Earth Science. 2007. 22(2): 879-887 (in Chinese)

Tong X G and Niu J Y. Effects of regional cap formation on oil and gas accumulation. Petroleum Exploration and Development. 1989. 16(4): 1-6 (in Chinese)

Wang M R, Hu W Y and Peng D H. Oil and gas potential of Jurassic strata in the northern margin of the Qaidam Basin. Petroleum Exploration and Development. 1997. 24(5): 20-26 (in Chinese)

$\mathrm{Xu} \mathrm{H} \mathrm{J.} \mathrm{The} \mathrm{oil-control} \mathrm{effect} \mathrm{of} \mathrm{the} \mathrm{palaeo-uplift} \mathrm{in} \mathrm{the} \mathrm{early} \mathrm{Hercynian}$ period in the Tarim Basin. Journal of Chengdu University of Technology (Science and Technology Edition). 2006. 33(5): 517-522 (in Chinese)

$\mathrm{Xu} \mathrm{X} \mathrm{H.} \mathrm{Formation} \mathrm{of} \mathrm{paleo-uplifts} \mathrm{and} \mathrm{petroleum} \mathrm{occurrence} \mathrm{in} \mathrm{the}$ Tarim Basin. Journal of Tongji University (Natural Science). 2004. 32(4): 461-466 (in Chinese)

Yuan M S, Liang S J, Yan L C, et al. Petroleum Geology and Exploration Practice in the Turpan-Hami Basin. Beijing: Petroleum Industry Press. 2002. 250-253 (in Chinese)
Zhang G Y, Zhao W Z, Zou C N, et al. Petroleum geological conditions and exploration potential in middle and lower combinations of onshore superimposed basins in China. Earth Science Frontiers. 2008. 15(2): 120-126 (in Chinese)

Zhang S C, Wang F Y, Zhang B M, et al. Middle-upper Ordovician source rock geochemistry of the Tarim Basin. Acta Petrolei Sinica. 2000. 21(6): 23-28 (in Chinese)

Zhang S C, Zhang B M, Bian L Z, et al. Development constraints of marine source rocks in China. Earth Science Frontiers. 2005. 12(3): 39-48 (in Chinese)

Zhang Z H, Yang Y C and Li W. The principles of reservoir geochemistry and its applications in petroleum exploration and reservoir appraisal. Marine Origin Petroleum Geology. 2006. 11(4): 39-48 (in Chinese)

Zhang Z M and Jia C Z. Paleohighs in the Craton Basin of Talimu and the exploration objectives. Journal of $\mathrm{Xi}$ 'an Petroleum Institute. 1997. 12(3): 8-16 (in Chinese)

Zhao J Z and Li Q M. Marine hydrocarbon accumulation stages and history in the craton area of the Tarim Basin. Chinese Science Bulletin. 2002. 47(supplement): 116-122 (in Chinese)

Zhao J Z, Pang W, Wu S B, et al. Geochronology and characteristics of marine hydrocarbon accumulation in the Tarim Basin. Chinese Journal of Geology. 2002. 37(supplement): 81-90 (in Chinese)

Zhao J Z, Wang Q H, Shi B H, et al. Marine hydrocarbon enrichment rules and palaeo-uplift-controlling hydrocarbon theory for the Paleozoic Tarim craton basin. Oil and Gas Geology. 2007. 28(6): 704-710 (in Chinese)

Zhao M J, Song Y, Pan W Q, et al. The overall approach of hydrocarbon filling periods and processes in sedimentary basins. Advances in Earth Science. 2004. 19(6): 939-947 (in Chinese)

Zhou X Y, Wang Z M, Yang H J, et al. Tazhong Ordovician condensate field in Tarim Basin. Marine Origin Petroleum Geology. 2006. 11(1): 45-52 (in Chinese)

(Edited by Hao Jie) 